\title{
Quantifying Tidal Movements of the Shore Crab Carcinus maenas on to Complex Epibenthic Bivalve Habitats
}

\author{
Andreas M. Waser ${ }^{1,2} \cdot$ Rob Dekker $^{1} \cdot$ Johannes IJ. Witte $^{1} \cdot$ Niamh McSweeney $^{1}$. \\ Bruno J. Ens ${ }^{3} \cdot$ Jaap van der Meer ${ }^{1,2}$
}

Received: 28 November 2016/Revised: 10 July 2017 / Accepted: 21 July 2017 /Published online: 11 August 2017

(C) The Author(s) 2017. This article is an open access publication

\begin{abstract}
Many subtidal predators undertake regular tidal migrations into intertidal areas in order to access abundant prey. One of the most productive habitats in soft bottom intertidal systems is formed by beds of epibenthic bivalves such as blue mussels (Mytilus edulis) and Pacific oysters (Crassostrea gigas). In the Dutch Wadden Sea, these bivalves might face substantial predation pressure by the shore crab (Carcinus maenas), which increased considerably in numbers during the last 20 years. However, the quantification of this species on bivalve beds is challenging, since most methods common for quantifying animal abundance in marine habitats cannot be used. This study investigated the potential of two methods to quantify the abundance of $C$. maenas on 14 epibenthic bivalve beds across the Dutch Wadden Sea. The use of the number of crabs migrating from subtidal towards intertidal areas as a proxy of abundance on bivalve beds yielded unreliable results. In contrast, crabs caught with traps on the beds were correlated with the abundance assessed on the surrounding bare flats by beam trawl and therefore provided usable results. The
\end{abstract}

Communicated by Patricia Ramey-Balci

Electronic supplementary material The online version of this article (doi:10.1007/s12237-017-0297-z) contains supplementary material, which is available to authorized users.

Andreas M. Waser

andreas.m.waser@gmail.com

1 Department of Coastal Systems, NIOZ Royal Netherlands Institute for Sea Research and Utrecht University, P.O. Box 59, 1790 AB Den Burg, Texel, The Netherlands

2 Department of Animal Ecology, VU University Amsterdam, de Boelelaan 1085, 1081 HV Amsterdam, The Netherlands

3 Sovon Dutch Centre for Field Ornithology, Sovon-Texel, P.O. Box 59, 1790 AB Den Burg, Texel, The Netherlands estimates, however, were only reliable for crabs exceeding $35 \mathrm{~mm}$ in carapace width (CW). The application of these estimates indicated that crab abundances on bivalve beds were influenced by the biogenic structure. Beds dominated by oysters attracted many large crabs $(>50-\mathrm{mm} \mathrm{CW})$, whereas abundances of medium-sized crabs (35-50-mm CW) showed no relationship to the oyster occurrence. The combination of traps and trawls is capable of quantifying crab abundance on bivalve beds, which offers the possibility to study biotic processes such as predator-prey interactions in these complex structures in more detail.

Keywords Tidal migration $\cdot$ Animal abundance $\cdot$ Wadden Sea $\cdot$ Mytilus edulis $\cdot$ Crassostrea gigas

\section{Introduction}

Shallow intertidal zones are very productive areas and feature a great abundance of benthic primary consumers, including many mollusk, polychaete, and crustacean species. With rising tide, many aquatic mobile secondary consumers such as fishes and decapods migrate from the subtidal zone into these productive areas to access abundant prey (Rilov and Schiel 2006; Jones and Shulman 2008; Silva et al. 2014). The highest productivity is often found in habitats rich in threedimensional structure, and one of these complex habitats in soft bottom intertidal systems is created by epibenthic bivalves such as blue mussels (Mytilus edulis L., 1758) and Pacific oysters (Crassostrea gigas Thunberg, 1793), which aggregate and accordingly form bivalve beds. These beds represent important features of the intertidal ecosystem by providing hard substrate, increasing habitat complexity, reducing hydrodynamics, and modifying the sediment by depositing 
large amounts of pseudo-feces and other fine particles (Gutierrez et al. 2003; van der Zee et al. 2012).

The Pacific oyster is native to coastal waters of the northwestern Pacific Ocean and nowadays has successfully invaded all temperate coastal ecosystems around the world (Ruesink et al. 2005). After the introduction of $C$. gigas into the European Wadden Sea in the 1970s (Troost 2010), many pure mussel beds developed into mixed bivalve beds or even into oyster-dominated beds since the late 1990s (Nehls et al. 2009; Troost 2010). Mussels and oysters similarly provide hard substrata for sessile species (Kochmann et al. 2008), but differ in their size, three-dimensional structure, heterogeneity, and formed micro-habitats (Gutierrez et al. 2003). Due to newly constructed biogenic reef structures, formed by the large-sized oysters, bivalve beds increased in habitat heterogeneity and in the amount of surface area for attachment and crevices for refuge of other organisms. Since both species also differ in their attachment mechanisms, aggregations of multiple specimens differ considerably in structural complexity. Mussels are adhered to the substratum via temporary byssus threads (Bell and Gosline 1996), and the continuous process of generating new threads leads to flexible and dynamic meshworks of individual mussels (van de Koppel et al. 2005). In contrast, Pacific oysters remain permanently attached to each other via an organic-inorganic adhesive (Burkett et al. 2010) and continuous larval settlement onto conspecifics leads to the creation of rigid and persisting structures (Walles et al. 2015). Consequently, the complex structures formed by these two bivalve species are likely to provide different resources in terms of nesting sites, shelter from predators, and feeding opportunities, thus potentially leading to differences in the species community (Markert et al. 2009). Moreover, the conversion of mussel beds into oyster-dominated beds may ultimately lead to a change of feeding opportunities for predators (Eschweiler and Christensen 2011; Waser et al. 2015, 2016a).

Crabs are among the most prominent predators that undertake tidal migrations to forage in intertidal areas during flood tides (Hamilton 1976; Hill et al. 1982; Holsman et al. 2006; Silva et al. 2014). These tidal migrations are also typical for the common shore crab (Carcinus maenas L., 1758) (e.g., Hunter and Naylor 1993; Silva et al. 2014), one of the most conspicuous and ecologically important benthic predators in many intertidal marine and estuarine environments around the world. It is native to coasts of Europe and North Africa and has successfully invaded many coastal areas worldwide (Carlton and Cohen 2003). While juvenile crabs remain in the high intertidal zone, with particularly high densities reported from complex biogenic structures like bivalve beds and seagrass meadows (Klein Breteler 1976a; Reise 1985; Thiel and Dernedde 1994; Moksnes 2002), adults tend to perform vertical tidal migrations, foraging in the intertidal during high tide and withdrawing to the subtidal zone during low tide (Crothers 1968; Hunter and Naylor 1993; Warman et al.
1993). Shore crabs are opportunistic feeders, with a preference for molluscan prey (Ropes 1968; Elner 1981; Raffaelli et al. 1989), and are capable of having drastic impacts on the stocks of commercial bivalve species (Ropes 1968; Walton et al. 2002; Murray et al. 2007). They generally forage on young bivalves up to shell lengths of about $3 \mathrm{~cm}$ with a preference for thinner-shelled species (Dare et al. 1983; Mascaró and Seed 2001; Miron et al. 2005; Pickering and Quijón 2011). Although multiple prey choice experiments indicated that Pacific oysters are less preferred prey of shore crabs (Dare et al. 1983; Mascaró and Seed 2001), field observations suggest that predation by $C$. maenas might have crucial effects on the survival of juvenile oysters (Walne and Davies 1977; Dare et al. 1983; Ruesink 2007; Kochmann and Crowe 2014).

In the Dutch Wadden Sea, annual sampling in the tidal channels revealed that the shore crab population increased considerably in the last 20 years (Tulp et al. 2012) and is therefore expected to have noticeable impacts on the different bivalve populations. However, little is known of the potential impact of C. maenas on epibenthic bivalve populations. Earlier studies assumed a considerable impact on the recruitment of M. edulis (McGrorty et al. 1990) and claimed a minor importance on adult mussels (Nehls et al. 1997). These argumentations are, however, purely speculative, in the absence of reliable estimates of the abundance of adult shore crabs on intertidal bivalve beds, due to the lack of an accurate and cost-efficient method to quantify the abundance of adult crabs present at high tide.

Moreover, little is known to what extent $C$. maenas responds to the change in habitat complexity due to the invasion of the Pacific oyster. Earlier studies which investigated the distribution of juvenile crabs in the Wadden Sea during low tide found no clear pattern in habitat preference. While Kochmann et al. (2008) report a preference for pure mussel habitats compared to mixed (mussel/oyster) and pure oyster habitats in young crabs of 5-10-mm CW in autumn and no preference in these crabs in the spring thereafter, Markert et al. (2009) found a much higher abundance of crabs in oysterdominated areas compared to mussel-rich sites. However, to our knowledge, no previous study focused on adult crabs, which are main bivalve predators, within the structures of the two bivalve species.

In the present study, we quantified the tidal migration of adult $C$. maenas on to bivalve beds differing in the bivalve composition (i.e., mussel dominated, oyster dominated, or balanced). To this end, we sampled crabs at 14 locations spread across the Dutch Wadden by using beam trawls and baited crab traps. We tested two different approaches to derive a quantitative estimate of crab abundance on bivalve beds: (1) beam trawling in subtidal gullies and on bare intertidal flats to assess the number of crabs migrating from the subtidal towards the intertidal and (2) combining crab traps placed on bivalve beds with absolute abundance estimates by beam 
trawling on bare flats adjacent to the bivalve beds. To investigate the differences in shore crab abundance among the different bivalve beds, we further tested to what extent crab abundance is influenced by prey density (juvenile bivalves) and by the predominance of Pacific oysters.

Our survey addresses the following questions: (1) How can the abundance of mobile $C$. maenas on bivalve beds at high tide be quantified? (2) What is the impact of the composition of the bivalve bed (the predominance of Pacific oysters or the density of bivalve recruits) on baited trap arrays and crab abundance?

\section{Material and Methods}

\section{Study Area}

The Wadden Sea is a shallow sea located in the southeastern part of the North Sea bordering the coastal mainland of Denmark, Germany, and the Netherlands. It is one of the world's largest coherent systems of intertidal sand and mud flats. The Dutch part of the Wadden Sea comprises an area of about $2500 \mathrm{~km}^{2}$ and contains coastal waters, intertidal sandbanks, mudflats, shallow subtidal flats, drainage gullies, and deeper inlets and channels. Tidal amplitudes gradually increase from about $1.5 \mathrm{~m}$ in the west to $3 \mathrm{~m}$ in the east. Up to $5 \%$ of the intertidal area is covered by epibenthic bivalve beds (Folmer et al. 2014), of which three different types can be distinguished: mussel-dominated beds, where oysters are absent or occur only in very low numbers; beds with a balanced proportion of mussels and oysters; and beds where oysters dominate in terms of biomass (van Stralen et al. 2012; Waser et al. 2016a).

\section{Properties of Bivalve Beds}

Overall, 14 locations spread across the Dutch part of the Wadden Sea were investigated in terms of shore crab abundance on bivalve beds (Fig. 1). The bivalve beds were monitored as part of a long-term investigation focusing on epibenthic bivalves and its potential predators (Waser et al. 2016a). Locations were selected in such way that they varied according to multiple characteristics (Table A1): distance to the shore, age (indication for amount of bivalve recruitment), and bivalve composition (ratio between oysters and mussels). Each bivalve bed was surveyed twice a year, in spring and autumn. For this study, we selected surveys performed shortly (up to about 1-2 months) before crabs were sampled at the same locations.

Firstly, the contours of each bed were determined by walking around the bed with a hand-held GPS device following a common definition of a mussel bed (de Vlas et al. 2005). The contours were used to delimit and create a set of multiple random sampling points. All created sample points were visited, and points covered by epibenthic bivalves (mussels/ oysters) were further sampled for benthos using a rectangular frame of a $0.0225-\mathrm{m}^{-2}(15 \times 15 \mathrm{~cm})$ surface. The samples were sieved (1-mm square meshes) in the field and sorted for mussels, oysters, and other bivalve species, which were subsequently counted and sized individually by means of digital calipers to the nearest $0.01 \mathrm{~mm}$. All bivalves smaller than $3 \mathrm{~cm}$ were considered as potential prey for shore crabs and were summed to determine the overall bivalve recruit density during spring/early summer for the different locations. It has to be noted that the chosen size threshold of $3 \mathrm{~cm}$ for juvenile bivalves is a rough approximation, and for some smaller species (i.e., Cerastoderma edule, Macoma balthica) also, adult individuals might be included. However, since adult individuals of these species occur in very low numbers, the proportions of adults in the recruit $(<3 \mathrm{~cm})$ densities are negligible.

In order to estimate the ratio between mussel and oyster biomass, the individual shell length $(L)$ of both species was converted into a volumetric length $(V)$, representing biomass, by a fixed dimensionless shape coefficient $\left(\delta_{M}\right): V=\left(\delta_{M} \times L\right)^{3}$. The shape coefficient is a parameter that relates the real length with the structural length in the context of the dynamic energy budget (DEB) theory (Kooijman 2010) and is well established for Pacific oysters (0.175, van der Veer et al. 2006), as well as for mussels (0.297, Saraiva et al. 2011).

\section{Shore Crab Sampling and Estimation of Crab Abundance}

Conventional methods such as visual estimation methods or direct trawling on the bivalve beds were considered unsuitable for this study because of the turbidity of mixed estuarine water resulting in low visibility (e.g., Philippart et al. 2013) and in order to prevent persisting damage to either the habitat, the community, or the sampling gear. Alternatively, we tested two other approaches to quantify the amount of $C$. maenas that use bivalve beds as foraging habitat during high tide: (1) beam trawling in the subtidal during high and low tides and during high tide on bare intertidal flats in order to estimate the number of crabs migrating towards the intertidal and (2) baited trap arrays on bivalve beds in combination with beam trawl sampling along the edges of the beds on the surrounding bare flats.

The shore crab sampling was executed in May/June of the years 2012 and 2013 (Waser et al. 2016b), except for one location (E002) which was investigated in September 2011 (Table 1). For logistical reasons, all sampling activities were performed during daytime. According to the study of Hunter and Naylor (1993), the numbers of migrating crabs do not significantly differ between daytime and nighttime. In general, each location (Fig. 1) was characterized by an intertidal bivalve bed surrounded by intertidal bare mud flats and subtidal areas (Fig. A1). However, not all locations were suitable for sampling crabs in the subtidal, since gullies or channels which allowed beam trawling by boat were situated too far from the 


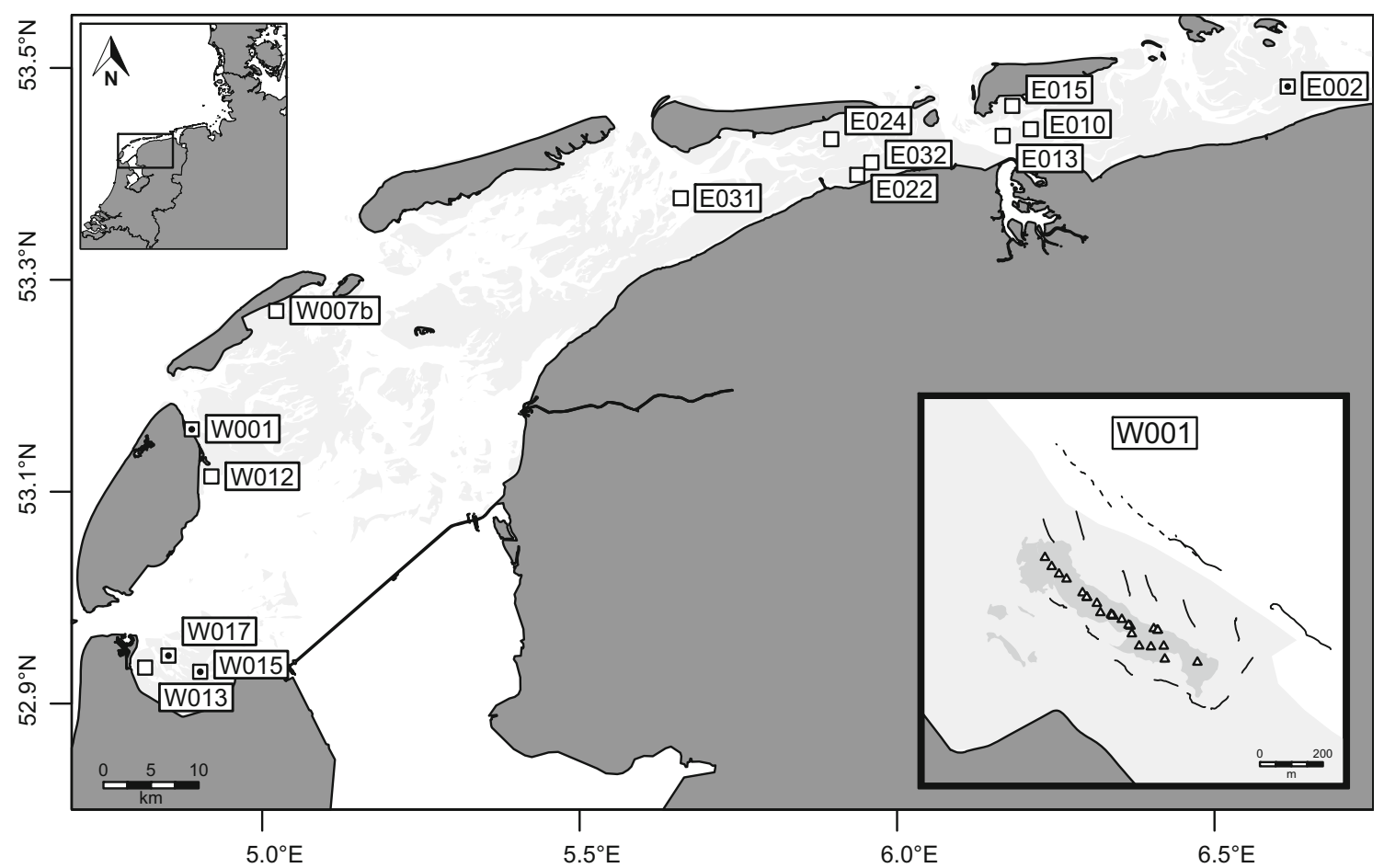

Fig. 1 Sampling locations (white squares) in the Dutch Wadden Sea. Locations where CPUE of traps was compared between intertidal bare flats and bivalve beds are indicated by black circles inside the white squares (for numbers of samples, see Table 1). White areas: subtidal; light gray areas: intertidal flats exposed during low tide; intermediate

respective beds. Hence, at these locations (E024 and E002), only intertidal sampling was carried out. Further, two bivalve beds (E022 and E032) were located in the vicinity of the same gully, and therefore, the sampling in the gully was used for both locations (Table 1). Shore crabs in the subtidal were caught around low and high tides $( \pm 1.5 \mathrm{~h})$. In general, sampling was done for both tidal levels with a 2-m beam trawl (mesh size of $5.5 \mathrm{~mm}$; one tickler chain) towed by a rubber dinghy. In a few cases ( 9 out of 73 hauls), sampling in the deep subtidal areas ( $>5-\mathrm{m}$ water depth) was carried out with a 3-m beam trawl (mesh size of $10 \mathrm{~mm}$; one tickler chain) towed by RV "Navicula" (Table 1). Since the study focused on the migrating part of the population and thus the larger individuals, the differences between the different mesh sizes in catching efficiency of the smallest crabs $(<10 \mathrm{~mm})$ could be ignored. Crabs on the intertidal mud flats were collected around high tide $( \pm 1.5 \mathrm{~h}$ ) by a 2 -m beam trawl (mesh size of $5.5 \mathrm{~mm}$; one tickler chain) towed by a rubber dinghy along the edges of the different bivalve beds (Fig. 1, inset). The depth at high tide on the intertidal flats between the different locations ranged from 0.5 to $1.5 \mathrm{~m}$. The location and exact distance of each haul were assessed using a hand-held GPS receiver. All catches were sorted immediately, and the numbers caught were converted into numbers per hectare $\left(10,000 \mathrm{~m}^{2}\right)$.

The relative abundance of shore crabs on bivalve beds and the surrounding flats was determined by trapping crabs with baited gray (in inset): mussel beds; dark gray: land. Inset: specific sampling design of one site. White triangles: positions of traps; lines: hauls taken by beam trawl (dashed lines: hauls at low tide; solid lines: hauls at high tide)

commercial plastic crayfish traps $(61 \mathrm{~cm}$ long $\times 31.5 \mathrm{~cm}$ wide $\times 25 \mathrm{~cm}$ high; mesh $10 \mathrm{~mm} \times 40 \mathrm{~mm}$ ) with inverted entry cones at both ends. The traps were scattered across the area during low tide and anchored into the substratum. The traps were baited with several (4-7) frozen juvenile $(<7 \mathrm{~cm})$ herring (Clupea harengus), set out overnight, and were emptied after about $18 \mathrm{~h}$ (ca. 1.5 high-tide periods). Although this method is limited to catching active, foraging crabs and is biased towards catching larger individuals (Williams and Hill 1982; Miller 1990), the catch perunit effort (CPUE) from traps can provide a proximate estimate of proportional abundance of crabs among different locations.

Immediately after collection, shore crabs were sized according to carapace width $(\mathrm{CW}$, the maximum distance between the two prominent lateral spines) with electronic calipers to the nearest $0.01 \mathrm{~mm}$ and assigned to one of three size classes: small $(\mathrm{CW}<35 \mathrm{~mm})$, medium $(\mathrm{CW} 35-50 \mathrm{~mm})$, or big $(\mathrm{CW}>50 \mathrm{~mm})$. The classification into size classes was based on (1) the migration behavior: small shore crabs $(<35$ $\mathrm{mm} \mathrm{CW}$ ) are mostly juveniles and burrow on the tidal flats during low tide (Hunter and Naylor 1993) and (2) size preference of mussels: crabs smaller than $50-\mathrm{mm} \mathrm{CW}$ hardly prey on mussels bigger than $1 \mathrm{~cm}$ in shell length (Elner and Hughes 1978; Smallegange and Van der Meer 2003; Waser et al. 2015). Moreover, it has to be noted that in the Wadden Sea, C. maenas typically reaches a maximum size of about $75-\mathrm{mm}$ $\mathrm{CW}$, but specimens larger than $65 \mathrm{~mm}$ are scarce (Klein 
Table 1 Overview of the location codes used in Fig. 1 as well as sampling dates and the number of samples being taken per different sample method

\begin{tabular}{|c|c|c|c|c|c|c|}
\hline $\begin{array}{l}\text { Location } \\
\text { code }\end{array}$ & Date & $\begin{array}{l}\text { No. of haul } \\
\text { subtidal } \\
\text { at low tide }\left(n_{L}\right)\end{array}$ & $\begin{array}{l}\text { No. of haul } \\
\text { subtidal } \\
\text { at high tide }\left(n_{H}\right)\end{array}$ & $\begin{array}{l}\text { No. of haul } \\
\text { intertidal } \\
\text { at high tide }\left(n_{I}\right)\end{array}$ & $\begin{array}{l}\text { No. of trap bivalve } \\
\text { bed at high tide } \\
\left(n_{B}\right)\end{array}$ & $\begin{array}{l}\text { No. of traps: comparison } \\
\text { intertidal and bivalve } \\
\text { beds }^{c}\end{array}$ \\
\hline W013 & May 29, 2012 & 2 & $3(2)$ & 10 & 18 & \\
\hline W017 & May 30, 2012 & $3(3)$ & $3(3)$ & 9 & 18 & $2 \times 15$ \\
\hline W015 & June 4, 2012 & 3 & 3 & 10 & 17 & $2 \times 9$ \\
\hline W001 & June 7, 2012 and June 8, 2012 & 3 & $2(1)$ & 13 & 30 & $2 \times 10$ \\
\hline W012 & June 5, 2012 & 3 & 3 & 10 & 18 & \\
\hline W007b & June 6, 2012 and June 7, 2012 & 3 & 3 & 7 & 19 & \\
\hline E031 & June 12, 2013 & 3 & 4 & 5 & 16 & \\
\hline E022 & June 11, 2013 & $4^{\mathrm{a}}$ & $4^{\mathrm{a}}$ & 10 & 10 & \\
\hline E032 & June 11, 2013 & $4^{\mathrm{a}}$ & $4^{\mathrm{a}}$ & 7 & 10 & \\
\hline E024 & June 13, 2013 & $\mathrm{NA}^{\mathrm{b}}$ & $\mathrm{NA}^{\mathrm{b}}$ & 9 & 18 & \\
\hline E013 & June 18, 2013 & 4 & 4 & 5 & 8 & \\
\hline E015 & June 19, 2013 & 4 & 4 & 10 & 16 & \\
\hline E010 & June 17, 2013 & 4 & 4 & 10 & 17 & \\
\hline E002 & September 8, 2011 & $\mathrm{NA}^{\mathrm{b}}$ & $\mathrm{NA}^{\mathrm{b}}$ & 9 & 8 & $2 \times 8$ \\
\hline
\end{tabular}

Numbers in parenthesis show the number of hauls taken by 3-m beam trawl. Locations in the western Dutch Wadden Sea are indicated by a "W," and accordingly, a location in the eastern part of the Dutch Wadden Sea is coded by an "E"

${ }^{\text {a }}$ Same adjacent gully

${ }^{\mathrm{b}}$ No subtidal sampling; gullies/channels located too far from the respective beds

${ }^{\mathrm{c}}$ For dates and details of the arrangements of crab traps, see "Shore Crab Sampling and Estimation of Crab Abundance" section

Breteler 1976b; Wolf 1998; Waser et al. 2016b). Therefore, the majority of crabs in the largest size class were between 50 and 65-mm CW.

\section{Tidal Migration as Proxy for Abundance on Bivalve Beds}

The relationship between the numbers of crabs during high and low tides can be described as $A_{S} L_{S}=A_{S} H_{S}+A_{I} H_{I}+A_{B} H_{B}$, where $A$ stands for surface area and $L$ and $H$ for crab abundance, in terms of numbers per surface area, at low tide and at high tide, respectively. The indices $S, I$, and $B$ refer, respectively, to the subtidal, the bare intertidal, and the bivalve beds. The mean abundance of crabs migrating to the intertidal $\left(M_{S}\right)$ is expressed as the difference in crab abundance in the subtidal between low and high tides: $M_{S}=L_{S}-H_{S}$. Accordingly, the abundance of crabs on bivalve beds at high tide based on tidal migration can be calculated as follows: $H_{B}=\frac{A_{S} M_{S}-A_{I} H_{I}}{A_{B}}$.

The surface area of each bivalve bed $\left(A_{B}\right)$ was obtained by determining the bed contours via GPS (see "Properties of Bivalve Beds" section). The area of the bare intertidal $\left(A_{I}\right)$ and the subtidal $\left(A_{S}\right)$ was obtained by dividing the area encircling the contours of the specific bivalve beds by a distance of $500 \mathrm{~m}$, approximating the suggested distance of tidal crab migrations (Dare and Edwards 1981; Holsman et al. 2006), into subtidal and intertidal sections. The partitioning into sub- and intertidal sections was based on bathymetric data (grid of $20 \times 20 \mathrm{~m}$ ) of the Dutch Wadden Sea provided by
Rijkswaterstaat (Dutch Ministry of Infrastructure and Environment; "vaklodingen," http://opendap.deltares.nl) together with information on local tidal amplitude (M2 tidal constituent, about $50 \%$ of the tidal amplitude, Duran-Matute et al. 2014). All grid points whose sum of bathymetric data and M2 tidal constituent was below 0 were defined as subtidal and points with a positive sum as intertidal. Adjacent intertidal and subtidal grid points were respectively converted into polygons, allowing us to define the sub- and intertidal area per location (Fig. A1).

\section{Proportionality Between Catches of Trawls on Intertidal Flats and Traps on Bivalve Beds}

In the second method, abundance of shore crabs on bivalve beds is estimated by relating absolute shore crab abundance on intertidal bare flats in close proximity to the bivalve beds to the relative abundance of crabs on the beds assessed by crab traps (CPUE). To determine the relationship in catches between crab traps on bivalve beds $\left(R_{B}\right)$ and the crab density on the bare intertidal bare flats $\left(H_{I}\right)$ adjacent to bivalve beds, general linear models (GLM) were applied. To normalize the data, abundances were transformed to $\log$ (value +1$)$.

In order to test to what extent the relative crab abundance on bivalve beds $\left(R_{B}\right)$ differs from the relative abundance on intertidal bare flats $\left(R_{I}\right)$, crab traps were deployed simultaneously in these two habitats on four locations: W017, 
W015, W001, and E002 (Fig. 1). While locations W001 and E002 were sampled in September 2011 with 10 and 8 traps, respectively, aligned on a straight transect (W001: $400 \mathrm{~m}$; E002 $1000 \mathrm{~m}$ ) per habitat, W015 was sampled in June 2012 and W017 in July 2012. In total, 9 traps per habitat were aligned along a 120-m-long transect at location W015, and at W017, 15 traps were randomly scattered at each habitat.

\section{Data Analysis}

For all analyses, relative and absolute shore crab abundances were subdivided into three classes based on life stage (small juveniles, medium-sized adults, and big-sized adults). Furthermore, the sum of all size classes (total catch) was included in plots.

Differences in relative abundance, the CPUE of crab traps, between bivalve beds $\left(R_{B}\right)$ and intertidal bare flats $\left(R_{I}\right)$ at four different locations, were tested with a MANOVA. Data were $\log (1+$ value $)$ transformed, to normalize the data.

The most trustworthy estimate of crab abundance on bivalve beds $\left(H_{B}\right)$ was used to test the effects of prey density (juvenile bivalves) and occurrence of Pacific oysters on the estimated crab abundance using Spearman's rank correlations. To exclude any variation based on season, location E002 (sampled in autumn 2011) was omitted for these analyses. As the main interest was the comparison among the crab abundance and bivalve bed parameters, locations from both years (2012 and 2013) were included in the analyses, despite the possibility that the difference in sampling year could confound location effects.

All statistical analyses were performed using R v3.2.1 (R Development Core Team 2015). For spatial data handling and production of the map, we used the R packages sp (Pebesma and Bivand 2015), rgeos (Bivand and Rundel 2015), rgdal (Bivand et al. 2015), maptools (Bivand and Lewin-Koh 2015), and raster (Hijmans 2015). For plotting, the package ggplot2 (Wickham 2009) was used.

\section{Results}

\section{Tidal Migration as Proxy for Abundance on Bivalve Beds}

Considering all individuals of all life stages, the number of crabs found on the intertidal bare flats was generally higher than the number of crabs estimated to migrate from the subtidal towards the intertidal (Fig. 2). This finding was mainly driven by the small crabs $(<35-\mathrm{mm} \mathrm{CW})$, which were numerous on the intertidal flats during high tide and rare in the subtidal. Hence, the number of crabs smaller than 35-mm $\mathrm{CW}$ migrating from the subtidal towards the intertidal was small (Fig. 2). For the other two size classes (medium and big), the number of crabs migrating from the subtidal towards the intertidal was higher than the number of crabs on bare intertidal flats at about half of the studied locations (Fig. 2). The fact that in most cases, the number on the intertidal $\left(A_{I} H_{I}\right)$ was higher than the number of migrating crabs $\left(A_{S} M_{S}\right)$ results in negative estimates of $H_{B}$ (Fig. 3). Thus, as this approach tends to predict negative values, it was not used to estimate crab abundance on bivalve beds.

\section{Proportionality Between Catches of Trawls on Intertidal Flats and Traps on Bivalve Beds}

The number of crabs caught on the bivalve beds by crab traps $\left(R_{B}\right)$ showed a clear relationship with the crab density assessed by beam trawling on the intertidal flats $\left(H_{I}\right)$ for medium-sized individuals (35-50-mm CW, GLM: $F 1,12=18.78, R^{2}=0.61$, $p \leq 0.001$, Fig. 4) and for big individuals ( $>50-\mathrm{mm} \mathrm{CW}$, GLM: $F 1,12=36, R^{2}=0.75, p \leq 0.001$, Fig. 5). The relationships are described by the equations: $y=1.1+1.16 x$ for medium crabs and $y=0.02+2.03 x$ for big crabs, respectively, where $y$ is the $\log$ abundance on intertidal bare flats $\left(H_{I}\right)$ and $x$ is the log CPUE on bivalve beds $\left(R_{B}\right)$. For the smallest crabs, the number of crabs caught on the beds showed no correlation with the crabs caught on bare intertidal flats at all (GLM: $F 1,12=0.004, R^{2}=0.0004$, $p=0.948$, Fig. 4). Small crabs were almost absent in the traps on the beds, but found in high numbers on the intertidal flats. Due to the discrepancy in the catch of the small crabs, the total number of crabs caught on the bivalve beds also did not show a correlation with the total crab density on intertidal flats (GLM: $F 1,12=0.564, R^{2}=0.045, p=0.467$, Fig. 4). Comparisons of catch rates of crab traps on bivalve beds $\left(R_{B}\right)$ and on intertidal bare flats $\left(R_{I}\right)$ indicate that CPUE of the traps per size category (small, medium, and big) did not differ between the two habitats (MANOVA: Wilks' lambda $=0.16, d f=3,1, p=0.496$, Fig. 5).

\section{Crab Abundance in Relation to Bivalve Bed Properties}

Based on the CPUE data on bivalve beds for the different locations and the linear relationships between relative and absolute crab abundance listed above, we can now estimate the densities of medium (35-50-mm CW) and big (> 50-mm $\mathrm{CW}$ ) crabs on the beds. We found the abundance on bivalve beds of medium-sized crabs (mean $251 \mathrm{n} \mathrm{ha}^{-1}$; range 40$580 \mathrm{n} \mathrm{ha}^{-1}$ ) to be more than twice as high as the abundance of big crabs (mean $107 \mathrm{n} \mathrm{ha}^{-1}$; range 35-190 $\mathrm{n} \mathrm{ha}^{-1}$ ). With these estimates, it is possible to investigate to what extent the density of bivalve recruits and the predominance of the Pacific oyster are related to the crab abundance. Overall, we found recruitment of five different bivalve species on the beds, with juveniles of M. edulis being the most abundant (Fig. 6). Although, $C$. gigas was present on most of the beds, individuals smaller than $3 \mathrm{~cm}$ of shell length were only found in very low numbers throughout all locations (Fig. 6). The bivalve recruit density showed no correlation with the abundance of 


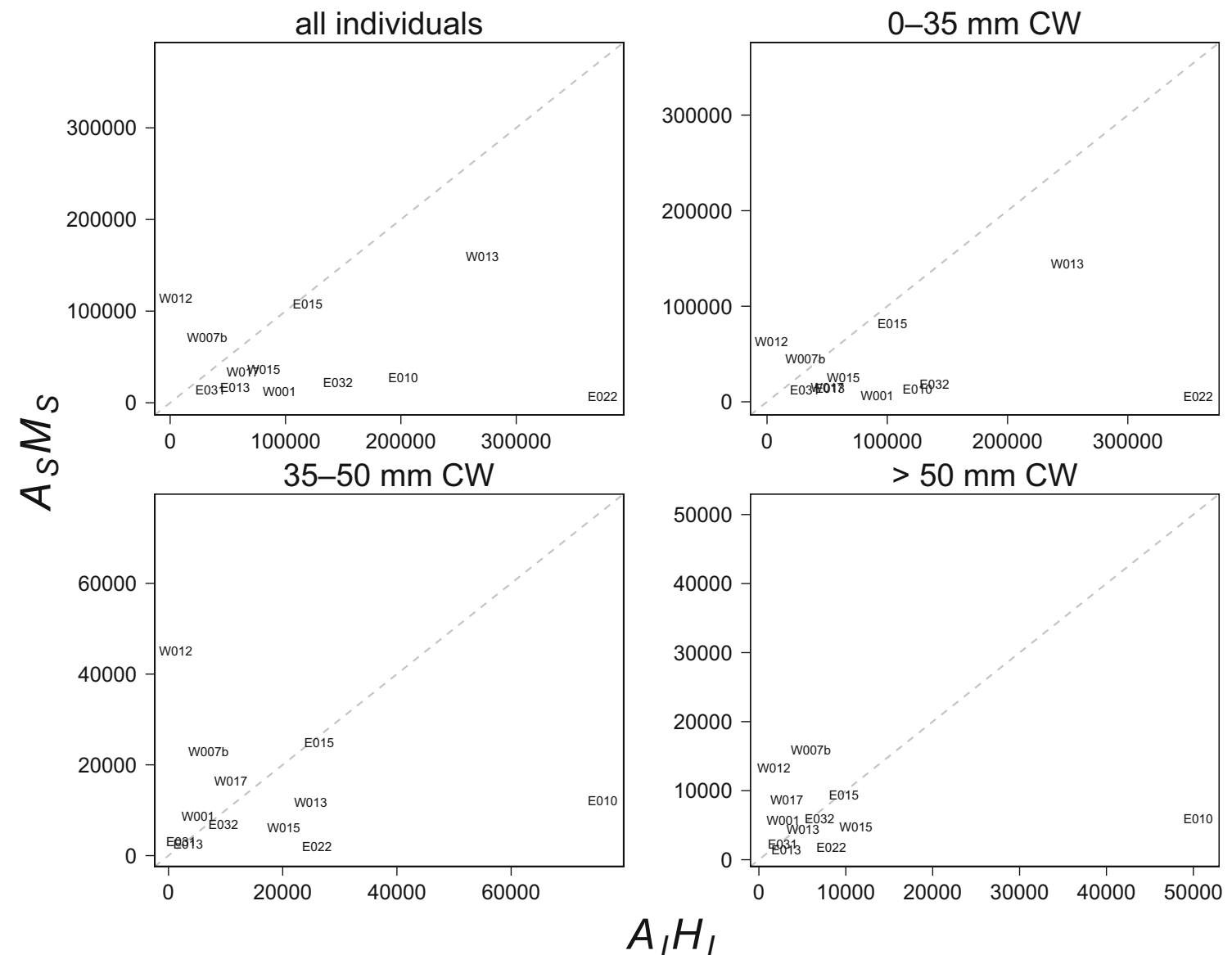

Fig. 2 Comparison of the mean number of different crab sizes on the intertidal bare flats $\left(A_{I} H_{I}\right)$ with the estimated number of crabs migrating from the subtidal towards the intertidal $\left(A_{S} M_{S}\right)$. The gray dashed line represents the $x=y$ line

both crab sizes (medium crabs: Spearman correlation, $S=542$, $\rho=-0.49, p=0.09$, Fig. 7a; big crabs: Spearman correlation, $S=532, \rho=-0.46, p=0.11$, Fig. 7c). While there was no significant effect of Pacific oyster predominance on the abundance of medium crabs (Spearman correlation, $S=191$, $\rho=0.48, p=0.1$, Fig. $7 \mathrm{~b}$ ), the abundance of big C. maenas was significantly correlated with the oyster occurrence (Spearman correlation, $S=66, \rho=0.82, p<0.001$, Fig. $7 \mathrm{~d}$ ).

\section{Discussion}

In this study, we investigated the tidal movements of adult shore crabs over epibenthic bivalve beds. To that extent, we explored the potential of two different methods for estimating the crab abundance on the beds during high tide. The first method, using crab migration as a proxy of abundance on bivalve beds, is based on the assumption that the vast majority of individuals are concentrated in the subtidal during low tide and parts of the population migrate to the intertidal with rising tide (Silva et al. 2014). Accordingly, differences in density between the two tidal levels in the subtidal zone should represent the fraction of individuals migrating to the intertidal and hence yield in an indirect estimate of species abundance for the intertidal at high tide. In our study, the estimated number of crabs emigrating from the subtidal towards the intertidal was in most cases lower than the estimated number of crabs in the intertidal at high tide. This resulted in negative estimates for the abundance on bivalve beds. One of the reasons for these negative abundance estimates is the behavior of juvenile crabs, which do not show tidal migration behavior and remain in the high intertidal zone (Crothers 1968; Hunter and Naylor 1993; Warman et al. 1993). However, negative abundances were also observed for adult crabs. A possible explanation for the false estimation of the abundance of adult crabs could be the classification of the intertidal area into subtidal and bare intertidal areas surrounding the bivalve beds, which was based on the distance that shore crabs can cover during tidal migrations. Very little is known about this migration distance, and for $C$. maenas, only the study of Dare and Edwards (1981) investigated the distance that crabs migrate during a single tide, by suggesting maximum migration distances of about $400 \mathrm{~m}$ in the Menai Strait (North Wales, UK). Moreover, Holsman et al. (2006) report tidal migration distances of up to $600 \mathrm{~m}$ into intertidal flats within a single tide for radio-tagged Dungeness crabs Cancer magister in Willapa 


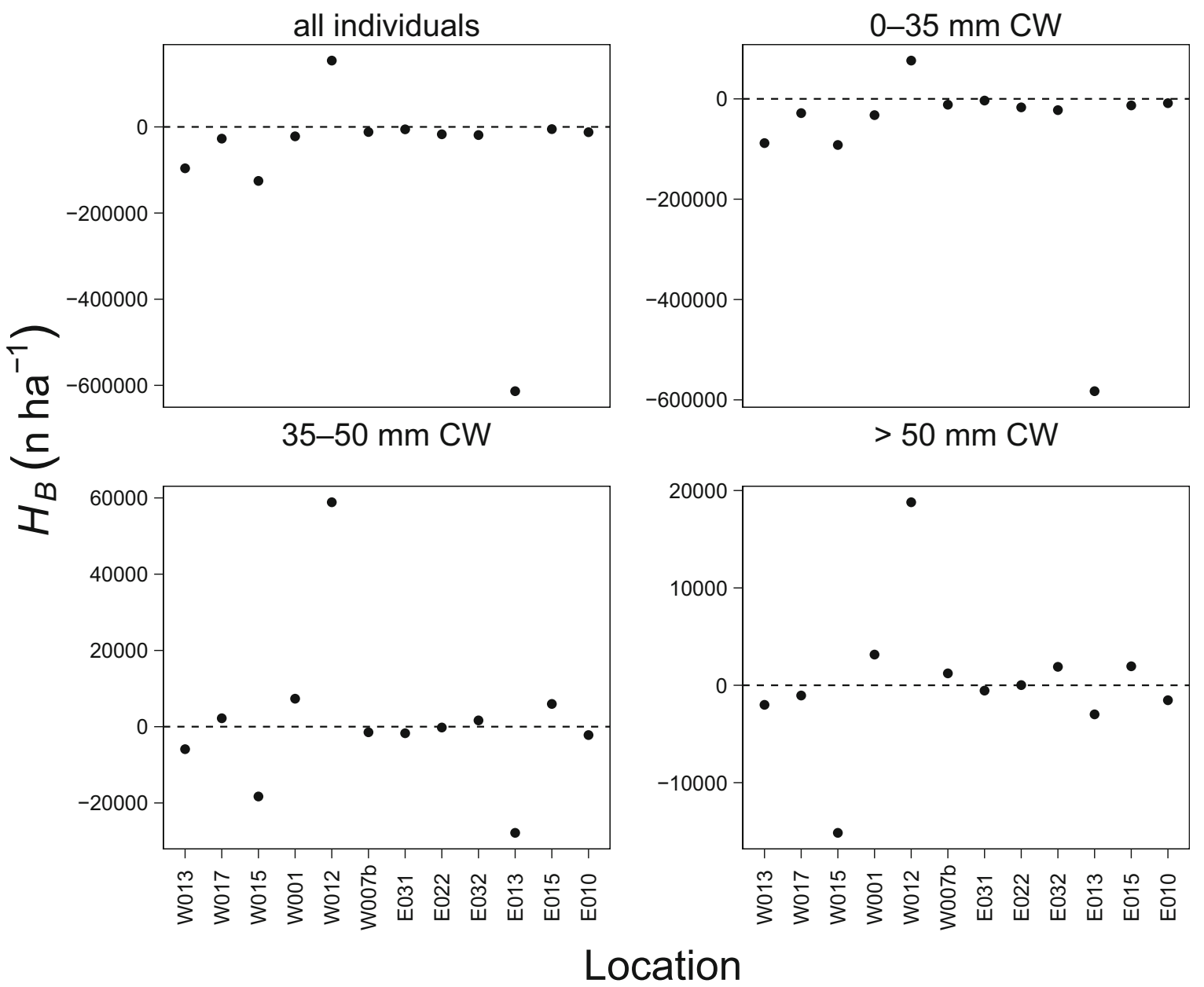

Fig. 3 Estimated density $\left(\mathrm{n} \mathrm{ha}^{-1}\right)$ of different crab sizes on the investigated bivalve beds $\left(H_{B}\right)$. The horizontal dashed line represents a crab density of 0

Bay (WA, USA). Further studies are needed to clarify whether these observed crab migration distances can be adopted for C. maenas in the Wadden Sea. However, based on the limited knowledge, we have chosen a maximum migration distance of $500 \mathrm{~m}$ as radius around the contours of the different bivalve beds to define subtidal and bare intertidal areas. With this chosen radius, most locations possessed a larger intertidal area compared to the subtidal, which resulted in higher values of $A_{I} H_{I}$ compared to $A_{S} M_{S}$, resulting in negative values for the crab abundance on bivalve beds. With larger migration distances (i.e., $1000 \mathrm{~m}$ or more) used as radius around the bivalve beds, the proportion subtidal/intertidal would have increased in favor for the subtidal at most of the studied locations, which would have resulted in less negative estimates for crab abundance on bivalve beds. Furthermore, the timing of the fishing might be very crucial for detecting migrating crabs. In order to sample crabs at multiple stations, we trawled for up to $3 \mathrm{~h}$ (ca. $1.5 \mathrm{~h}$ before and after the exact tide level) per bivalve bed location. This time frame may have been too wide, such that crabs may not have yet arrived or have already left the gullies at the time of sampling. In addition, due to logistic reasons, it was not always possible to sample crabs during high tide simultaneously in the subtidal and intertidal, which might also have influenced the results.

In the second method, a combination of baited crab traps and intertidal beam trawling during high tide was used to convert the relative abundance obtained on the beds $\left(R_{B}\right)$ into an absolute estimate $\left(H_{B}\right)$. In general, this method provided trustworthy estimates of crab abundance on bivalve beds, but the outcomes varied with crab size. While for adult crabs (size: medium and big), the numbers of individuals caught on the different beds were correlated to the abundance assessed on the adjacent bare flats, small crabs showed no correlation between the trap and the trawl samples. The strong mismatch in the small crabs resulted from the low catches of the traps on the beds. Yet, the evidence acquired with sampling during low tide indicates that the abundance of small crabs is higher on bivalve beds than on bare sand flats (Klein Breteler 1976a; Thiel and Dernedde 1994; Moksnes 2002), suggesting that our method applied may not be suitable to sample small crabs in this habitat. Generally, catches of crab species in baited traps are biased towards larger individuals (Williams and Hill 1982; Miller 1990). It is possible that the small crabs either avoided entering the traps due to the presence of bigger 
Fig. 4 Relationship between the number of the different crab sizes caught in the traps $\left(R_{B}, \log \right.$ $\mathrm{CPUE} \pm \mathrm{SE}$ ) on bivalve beds and the density on the intertidal bare flats sampled by beam trawl $\left(H_{I}\right.$, $\left.\log \mathrm{nha}^{-1} \pm \mathrm{SE}\right)$. The relationships are described by the equations: $y=1.1+1.16 x$ for crabs of 35-50-mm CW and $y=$ $0.02+2.03 x$ for crabs bigger than 50-mm CW, respectively

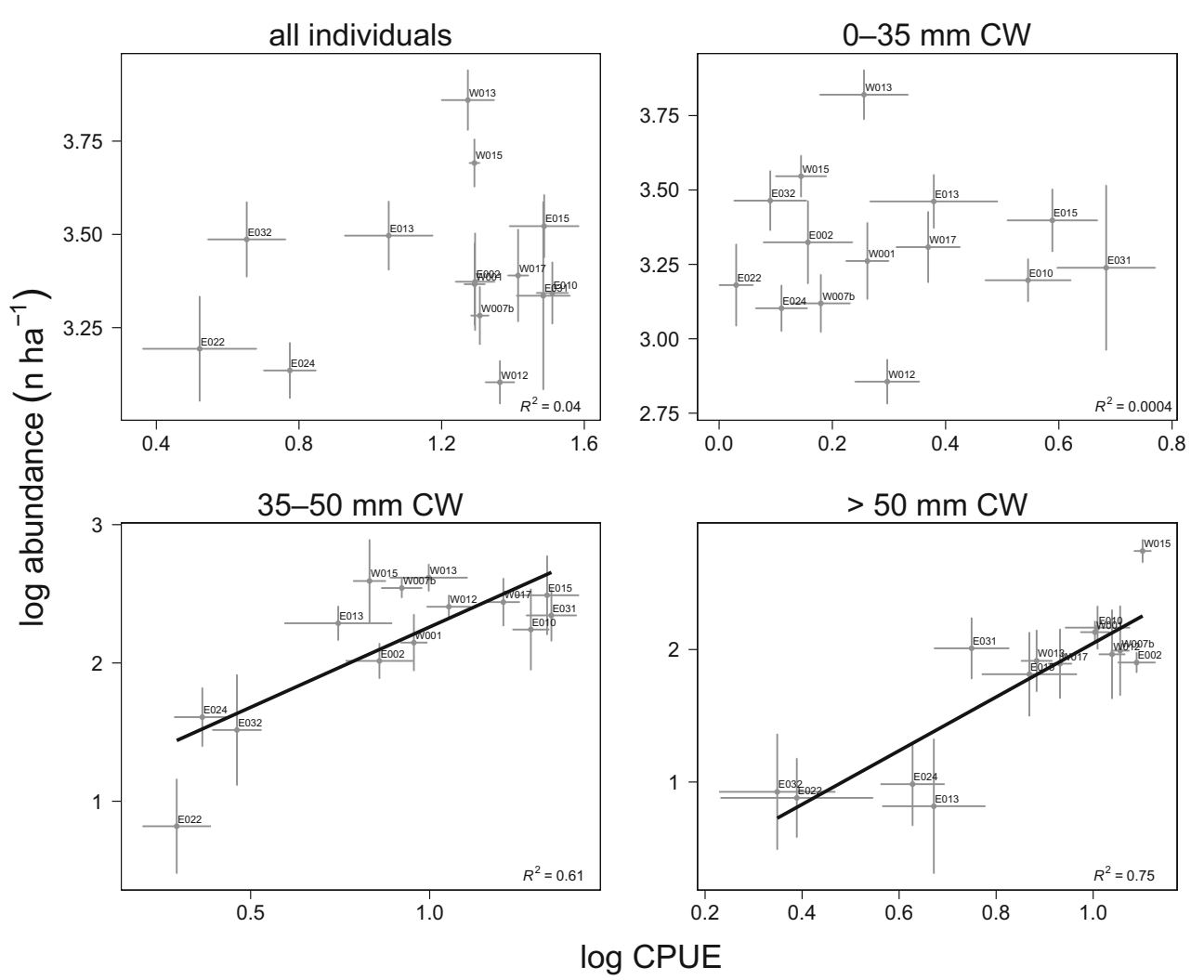

conspecifics, which are superior competitors (Smallegange and van der Meer 2006; Fletcher and Hardege 2009), or the small crabs might have entered the traps, but escaped before traps were retrieved. In order to detect the exact mechanisms and the behavior of small crabs in relation to traps, further studies are needed, such as detailed video observations of crabs attracted to traps. However, edited traps, where the entry size was reduced using cable ties, preventing larger crabs to enter, also barely caught any crabs smaller than $35-\mathrm{mm} \mathrm{CW}$ (Waser, unpublished data), suggesting that the crabs escaped before trap retrieval. Regardless of the exact mechanisms, the combined use of baited traps and beam trawl is only beneficial for estimating abundances of C. maenas larger than 35-mm $\mathrm{CW}$. However, other methods such as sampling with sediment cores at low tide are commonly used for abundance estimates of juvenile crabs on structural complex habitats (e.g., Klein Breteler 1976a). Since these crabs do not migrate between the tides (e.g., Hunter and Naylor 1993), abundances of these juveniles measured at low tide also apply for high tide at the same location.

As both sampling methods were applied in two different habitats, i.e., bare intertidal flats and bivalve beds, it is also of interest to ascertain to what extent trap catches differ between the two habitats. Although we expected considerable higher crab numbers in traps placed on bivalve beds, due to a higher productivity, we found no significant difference in crab catches between traps placed on bivalve beds and intertidal bare flats. This observation might be based on either a reduced catch of traps placed on the beds and on the other hand increased trap catches on bare flats. Possible reasons for reduced catches of traps are that crabs might have stopped entering the traps after a while, either because traps became too crowded (saturation effect; Miller 1990), making it likely to prevent more crabs from entering the traps, or attraction to traps might have been reduced (Miller 1990), since bait fish was devoured by already caught crabs. In contrast, traps might additionally attract crabs through the provision of shelter. It is likely that the effects of shelter provision are more important in habitats of low structural complexity, such as bare intertidal flats. Moreover, it is possible that traps placed on bare flats also attracted and caught some crabs that initially were migrating towards the bivalve beds.

With the combination of traps and beam trawl, we estimated an average abundance of about $360 \mathrm{n} \mathrm{ha}^{-1}$ for adult shore crabs (250 and $110 \mathrm{n} \mathrm{ha}^{-1}$ for medium and big crabs, respectively) on epibenthic bivalve beds in the Dutch Wadden Sea. This abundance estimate is more or less in agreement with the findings of a study that investigated shore crab abundance at various different habitats in the Northern Wadden Sea (Scherer and Reise 1981). Although Scherer and Reise (1981) did not explicitly sample C. maenas on mussel beds, they assumed a crab abundance of about $1500 \mathrm{n} \mathrm{ha}^{-1}$ on intertidal mussel beds. The difference in crab abundance between the two studies is mainly based on different size spectra 
Fig. 5 Comparison of relative abundance between crabs of different size classes on intertidal bare flats $\left(R_{I}\right)$ and crabs on bivalve beds $\left(R_{B}\right)$ caught with crab traps (CPUE). Box and whisker plots indicate the median (horizontal line inside the box), interquartile range (box), range (whiskers), and outliers (small dots)

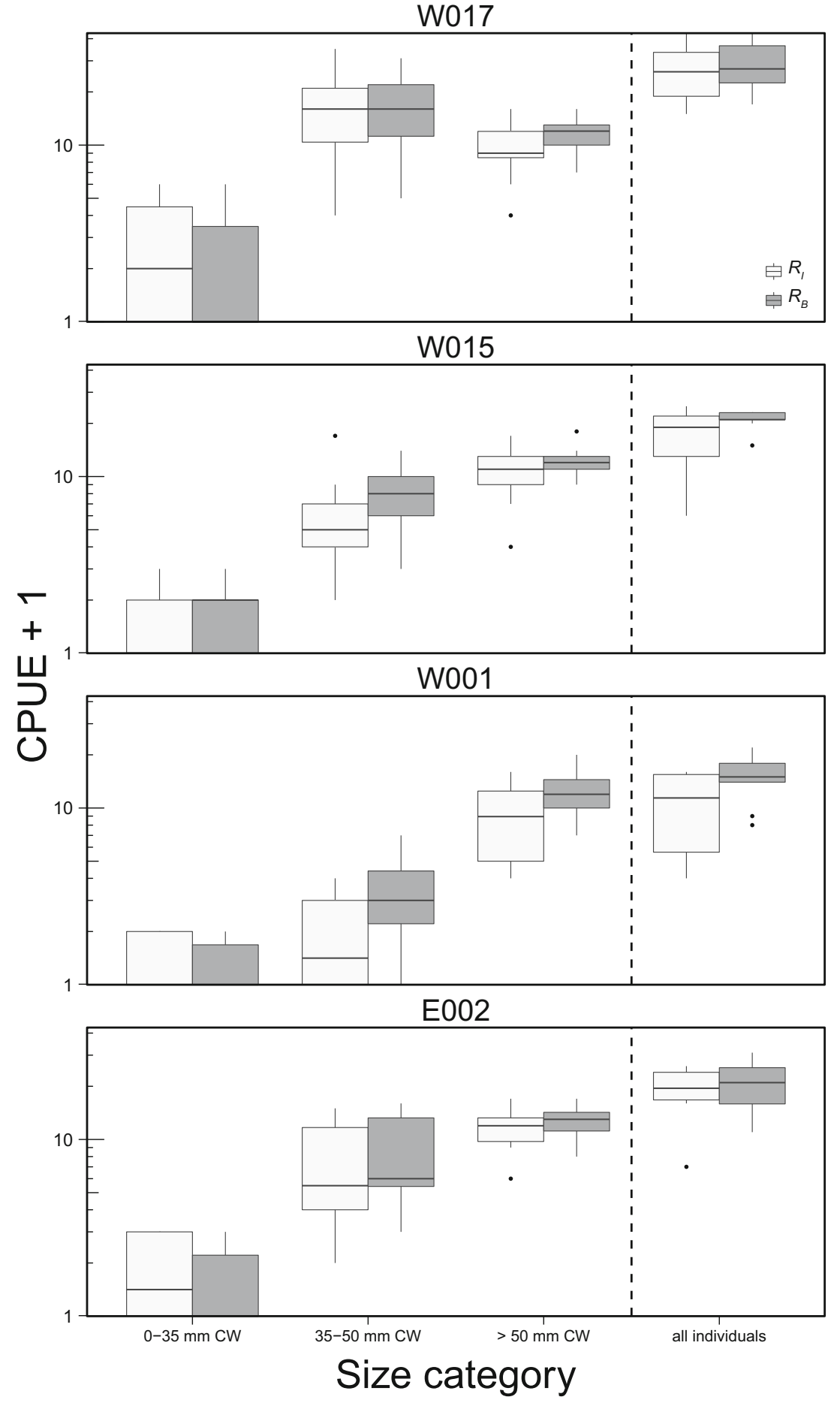

used to derive the estimates of crab abundance. While our study focused on crabs larger than 35-mm CW, Scherer and Reise (1981) also considered smaller-sized crabs with minimum CW of $15 \mathrm{~mm}$.

Shore crabs are opportunistic feeders, with a preference for mollusks (Ropes 1968; Elner 1981; Raffaelli et al. 1989). Furthermore, they are known to primarily feed on the most abundant prey species (Scherer and Reise 1981). On all studied bivalve beds, the species with the highest abundance of individuals vulnerable to crab predation $(<3-\mathrm{cm}$ shell length) was M. edulis. Except for the two beds (W013 and W017), small individuals of other bivalves were scarce. Although some beds showed a high density and biomass of the Pacific oyster (Table A1), densities of small individuals of $C$. gigas $(<3-\mathrm{cm}$ shell length) were low at all studied locations. That indicates that for the crabs sampled in our study, recruitment stages of $C$. gigas 
Fig. 6 Mean density $\left(\mathrm{n} \mathrm{m}^{-2}\right)$ of juveniles (individuals smaller than $3 \mathrm{~cm}$ ) of the different bivalve species (Crassostrea gigas, Macoma balthica, Mya arenaria, Cerastoderma edule, Mytilus edulis) on bivalve-covered patches at 13 different bivalve beds in spring/early summer

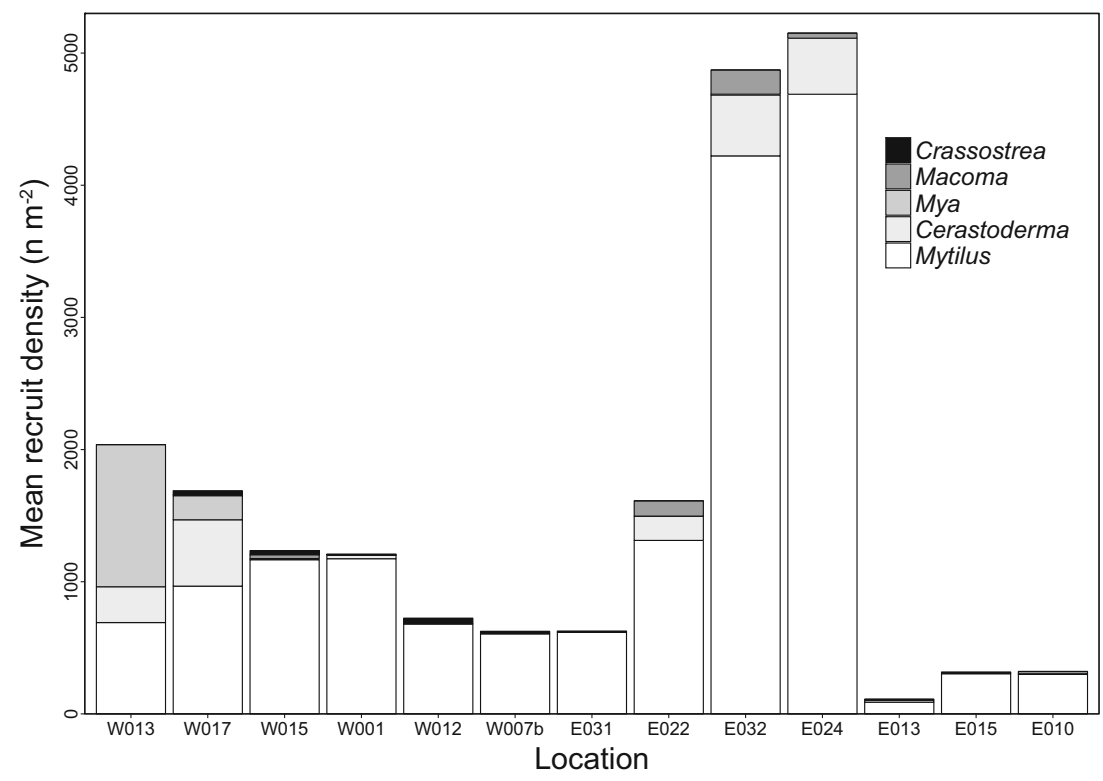

are of minor importance. The estimates of crab abundance on bivalve beds given above allowed us to assess general predation rates on intertidal mussels. Smallegange (2007) investigated the consumption rates of satiated shore crabs feeding on M. edulis in laboratory experiments, which indicated that medium crabs consumed on average about three mussels of 18-mm length (CW $\sim 35 \mathrm{~mm}$ : two mussels; $\mathrm{CW} \sim 45 \mathrm{~mm}$ : four mussels) and big crabs (CW $\sim 55 \mathrm{~mm}$ ) foraged on about 4.5 mussels within a period of
$6 \mathrm{~h}$. For practical reasons, we considered the foraging period of $6 \mathrm{~h}$, used in the experiments of Smallegange (2007), to approximate the inundation time of bivalve beds during a single high tide. Considering that crabs solely forage on mussels, C. maenas reaches daily predation rates of about 2500 mussels (medium crabs 750 mussels within 6 h; big crabs 500 mussels/6 h) per 1 ha of bivalve bed. As shore crabs occur on intertidal flats for approximately 180 days a year (May-October), spending cold
Fig. 7 Crab abundance $\left(\mathrm{n} \mathrm{ha}^{-1}\right)$ on bivalve beds of $\mathbf{a}, \mathbf{b}$ mediumsized (35-50-mm CW) and $\mathbf{c}, \mathbf{d}$ big-sized Carcinus maenas ( $>50$ $\mathrm{mm} \mathrm{CW}$ ) depending on $\mathbf{a}, \mathbf{c}$ density of juvenile bivalves $(<3 \mathrm{~cm})$ on bivalve-covered patches $\left(\mathrm{n} \mathrm{m}^{-2}\right)$ and $\mathbf{b}, \mathbf{d}$ the fraction of Pacific oysters of the bivalve biomass $(\%)$
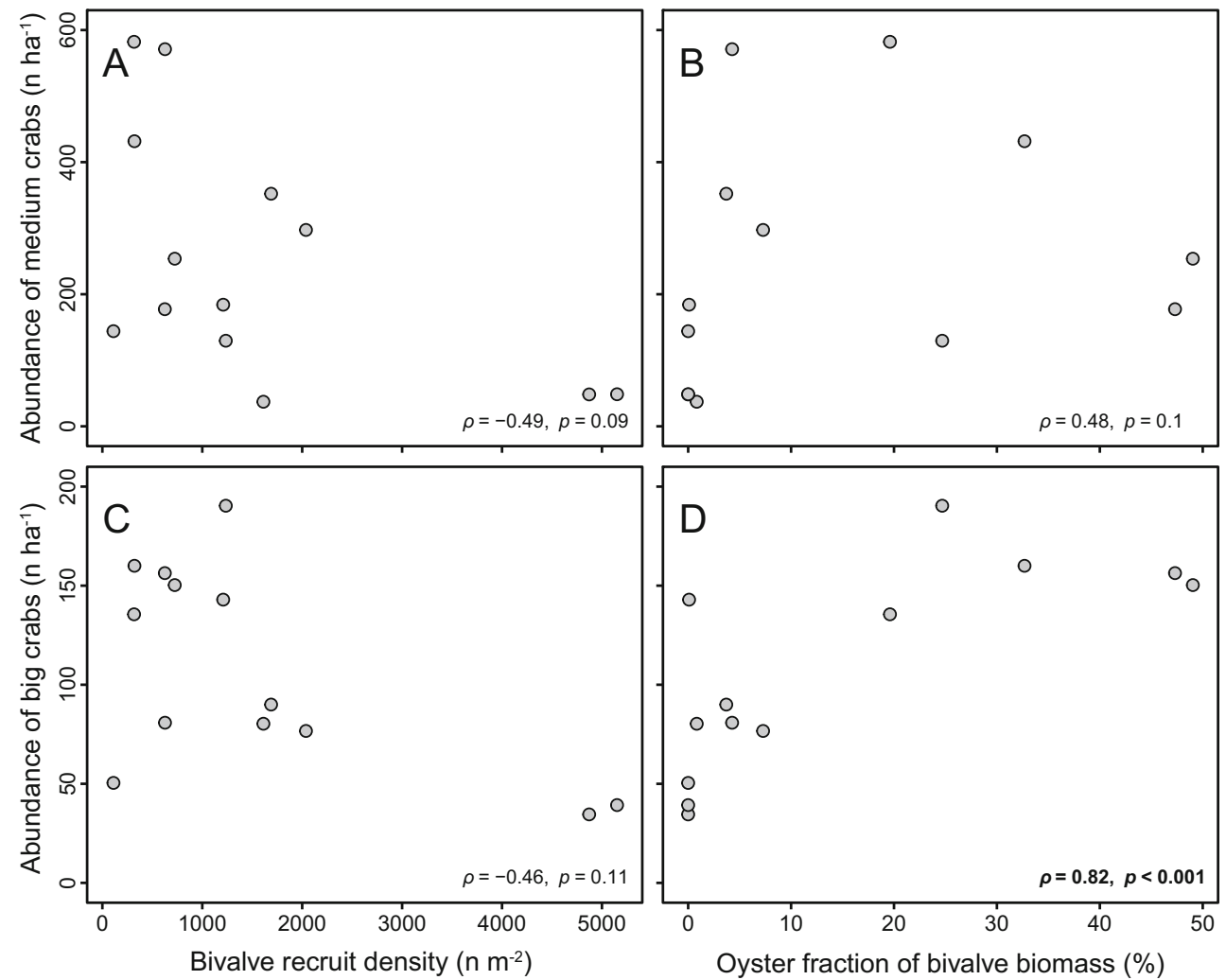
periods in deeper waters (Naylor 1962, Thiel and Dernedde 1994), annual predation rates of shore crabs amount to 450,000 mussels $(270,000$ and 180,000 mussels for medium and big crabs, respectively) per 1 ha of bivalve bed.

Furthermore, we expected the abundance of crabs to increase with prey density (juvenile bivalves), but abundances of both medium and big crabs were not significantly positively correlated with the bivalve recruit density. If anything, the correlation was negative. How can we explain the absence or even a negative relationship between crabs and bivalve recruitment? Perhaps, the bivalve recruit densities assessed prior to the shore crab sampling decreased substantially between the two sampling occasions, due to either mortality (predation) or growth, leading to the observed patterns between bivalve recruitment and shore crabs. Moreover, the two beds with the highest density of small bivalves $\left(\sim 5000 \mathrm{n} \mathrm{m}^{-2}\right)$ showed very low crab abundances, which also considerably affected the observed relationship between crab abundance and bivalve recruit density. In general, the success of bivalve recruitment is strongly related to predator abundance (e.g., Beukema and Dekker 2014), suggesting that recruit density is particularly high at locations where (crab) predation is low.

Although differences in habitat complexity between oysterand mussel-dominated beds were not quantified explicitly in the present study, a much higher habitat complexity in oyster-rich beds seems likely, since oysters are multiple times larger than mussels. In terms of crab abundance, earlier studies report mixed results concerning the habitat preferences of juvenile C. maenas in oyster and mussel structures (Kochmann et al. 2008, Markert et al. 2009) so that it is difficult to judge whether juvenile crabs show a preference for oyster-dominated bivalve structures. We found that beds with high oyster occurrences favor the abundance of larger crabs, while the abundance of medium-sized crabs seems to be unrelated to the oysters. The increase in interstitial space, attributed to the increase of oyster dominance, may offer suitable refuges and attract also adult crabs. As big C. maenas are superior in competing for resources compared to smaller conspecifics (Smallegange and van der Meer 2006; Fletcher and Hardege 2009), high densities of large crabs would presumably prevent smaller-sized individuals of finding shelter in the interstitial space and might explain why smaller-sized crabs do not occur in high numbers at exactly the same locations. Likewise, previous studies found dominant crab species to be present in high densities in habitats of high complexity whereas species being weaker competitors were found avoiding those areas occupied by dominant crabs (Lohrer et al. 2000; Holsman et al. 2006).

In conclusion, we could show that the combination of baited traps and beam trawling is a suitable method to estimate the abundance of shore crabs larger than $35 \mathrm{~mm}$ in $\mathrm{CW}$ on epibenthic bivalve beds in soft bottom intertidal systems. The method developed in this study provides one possible solution for future monitoring of shore crab populations on epibenthic bivalve beds. It also offers the possibility to study biotic processes such as predator-prey interactions in these complex structures in more detail. While the focus was the shore crab on intertidal bivalve beds, there are important implications for surveys of other species (e.g., other crab species or demersal fish species) and of other intertidal habitats (e.g., rocky intertidal and intertidal seagrass beds). Different species and different habitats may require an adjusted set of sampling gears to adequately survey the populations in question.

Acknowledgments This study was carried out as part of the project Mosselwad, which is funded by the Dutch Waddenfonds (WF 203919), the Ministry of Infrastructure and Environment (Rijkswaterstaat), and the provinces of Fryslân and Noord Holland. We thank Bram Fey, Klaas-Jan Daalder, Wim-Jan Boon, and Hein de Vries, crew of the Royal NIOZ research vessel RV Navicula, for their help. We also wish to thank Afra Asjes, Annabelle Dairain, Niel de Jong, Erika Koelemij, Lotte Meeuwissen, Felipe Ribas, Anneke Rippen, Robert Twijnstra, Marin van Regteren, and Kai Wätjen who helped in the sampling and processing of shore crabs. We thank Arnold Bakker, Tristan Biggs, Maarten Brugge, Annabelle Dairain, Erika Koelemij, Lotte Meeuwissen, Anneke Rippen, Sofia Saraiva, Cor Sonneveld, and Arno wa Kangeri for helping in sampling and processing bivalves on the different bivalve beds. Furthermore, we thank Patricia Ramey-Balci and two anonymous reviewers for constructive feedback on an earlier draft of the manuscript.

Open Access This article is distributed under the terms of the Creative Commons Attribution 4.0 International License (http:// creativecommons.org/licenses/by/4.0/), which permits unrestricted use, distribution, and reproduction in any medium, provided you give appropriate credit to the original author(s) and the source, provide a link to the Creative Commons license, and indicate if changes were made.

\section{References}

Bell, E.C., and J.M. Gosline. 1996. Mechanical design of mussel byssus: material yield enhances attachment strength. The Journal of Experimental Biology 199: 1005-1017.

Beukema, J.J., and R. Dekker. 2014. Variability in predator abundance links winter temperatures and bivalve recruitment: correlative evidence from long-term data in a tidal flat. Marine Ecology Progress Series 513: 1-15. doi:10.3354/meps10978.

Bivand R, and Lewin-Koh N (2015) maptools: tools for reading and handling spatial objects. $\mathrm{R}$ package version $0.8-36$. https://cran.rproject.org/web/packages/maptools/maptools.pdf

Bivand R, and Rundel C (2015) rgeos: interface to Geometry EngineOpen Source (GEOS). R package version 0.3-11. https://cran.rproject.org/web/packages/rgeos/rgeos.pdf

Bivand R, Keitt T, and Rowlingson B (2015) rgdal: bindings for the Geospatial Data Abstraction Library. R package version 1.0-4. https://cran.r-project.org/web/packages/rgdal/rgdal.pdf

Burkett, J.R., L.M. Hight, P. Kenny, and J.J. Wilker. 2010. Oysters produce an organic-inorganic adhesive for intertidal reef construction. Journal of the American Chemical Society 132: 12531-12533. doi: 10.1021/ja104996y.

Carlton, J.T., and A.N. Cohen. 2003. Episodic global dispersal in shallow water marine organisms: the case history of the European shore crabs Carcinus maenas and C. aestuarii. Journal of Biogeography 30: 1809-1820. doi:10.1111/j.1365-2699.2003.00962.x.

Crothers, J.H. 1968. The biology of the shore crab Carcinus maenas (L.) 2. The life of the adult crab. Field Studies 2: 579-614. 
Dare, P.J., and D.B. Edwards. 1981. Underwater television observations on the intertidal movements of shore crabs, Carcinus maenas, across a mudflat. Journal of the Marine Biological Association of the United Kingdom 61: 107-116. doi:10.1017/S002531540004594X.

Dare PJ, Davies G, and Edwards DB (1983) Predation on juvenile Pacific oysters (Crassostrea gigas Thunberg) and mussels (Mytilus edulis L.) by shore crabs (Carcinus maenas L.) Ministry of agriculture, fisheries and food directorate of fisheries research, Lowestoft, U.K., Fisheries Research Technical Report No. 73.

de Vlas, J., A.G. Brinkman, C. Buschbaum, N. Dankers, M. Herlyn, P.S. Kristensen, G. Millat, et al. 2005. Intertidal blue mussel beds. Trilateral monitoring and assessment group. Wilhelmshaven: Common Wadden Sea Secretariat.

Duran-Matute, M., T. Gerkema, G.J. de Boer, J.J. Nauw, and U. Gräwe. 2014. Residual circulation and freshwater transport in the Dutch Wadden Sea: a numerical modelling study. Ocean Science 10: 611-632. doi:10.5194/os-10-611-2014.

Elner, R.W. 1981. Diet of green crab Carcinus maenas (L.) from Port Herbert, southwestern Nova Scotia. Journal of Shellfish Research 1: 89-94. doi:10.2983/035.029.0302.

Elner, R.W., and R.N. Hughes. 1978. Energy maximization in the diet of the shore crab, Carcinus maenas. The Journal of Animal Ecology 47: 103. doi: $10.2307 / 3925$.

Eschweiler, N., and H.T. Christensen. 2011. Trade-off between increased survival and reduced growth for blue mussels living on Pacific oyster reefs. Journal of Experimental Marine Biology and Ecology 403: 90-95. doi:10.1016/j.jembe.2011.04.010.

Fletcher, N., and J.D. Hardege. 2009. The cost of conflict: agonistic encounters influence responses to chemical signals in the European shore crab. Animal Behaviour 77: 357-361. doi:10. 1016/j.anbehav.2008.10.007

Folmer, E.O., J. Drent, K. Troost, H. Büttger, N. Dankers, J.M. Jansen, M. van Stralen, G. Millat, M. Herlyn, and C.J.M. Philippart. 2014. Large-scale spatial dynamics of intertidal mussel (Mytilus edulis L.) bed coverage in the German and Dutch Wadden Sea. Ecosystems 17: 550-566. doi:10.1007/s10021-013-9742-4.

Gutierrez, J.L., C.G. Jones, D.L. Strayer, and O.O. Iribarne. 2003. Mollusks as ecosystem engineers: the role of shell production in aquatic habitats. Oikos 101: 79-90. doi:10.1034/j.1600-0706.2003.12322.x.

Hamilton, P.V. 1976. Predation on Littorina irrorata (Mollusca: Gastropoda) by Callinectes sapidus (Crustacea: Portunidae). Bulletin of Marine Science 26: 403-409.

Hijmans RJ (2015) raster: geographic data analysis and modeling. R package version 2.4-15. https://cran.r-project.org/web/packages/ raster/raster.pdf

Hill, B.J., M.J. Williams, and P. Dutton. 1982. Distribution of juvenile, subadult and adult Scylla serrata (Crustacea: Portunidae) on tidal flats in Australia. Marine Biology 69: 117-120. doi:10.1007/ BF00396967.

Holsman, K.K., P.S. McDonald, and D.A. Armstrong. 2006. Intertidal migration and habitat use by subadult Dungeness crab Cancer magister in a NE Pacific estuary. Marine Ecology Progress Series 308: 183-195. doi:10.3354/meps308183.

Hunter, E., and E. Naylor. 1993. Intertidal migration by the shore crab Carcinus maenas. Marine Ecology Progress Series 101: 131-138. doi:10.3354/meps101131.

Jones, P.L., and M.J. Shulman. 2008. Subtidal-intertidal trophic links: American lobsters [Homarus americanus (Milne-Edwards)] forage in the intertidal zone on nocturnal high tides. Journal of Experimental Marine Biology and Ecology 361: 98-103. doi:10. 1016/j.jembe.2008.05.004.

Klein Breteler, W.C.M. 1976a. Settlement, growth and production of the shore crab, Carcinus maenas, on tidal flats in the Dutch Wadden Sea. Netherlands Journal of Sea Research 10: 354-376. doi:10. 1016/0077-7579(76)90011-9.
Klein Breteler, W.C.M. 1976b. Migration of the shore crab, Carcinus maenas, in the Dutch Wadden Sea. Netherlands Journal of Sea Research 10: 338-353. doi:10.1016/0077-7579(76)90010-7.

Kochmann, J., and T.P. Crowe. 2014. Effects of native macroalgae and predators on survival, condition and growth of non-indigenous Pacific oysters (Crassostrea gigas). Journal of Experimental Marine Biology and Ecology 451: 122-129. doi:10.1016/j.jembe. 2013.11.007.

Kochmann, J., C. Buschbaum, N. Volkenborn, and K. Reise. 2008. Shift from native mussels to alien oysters: differential effects of ecosystem engineers. Journal of Experimental Marine Biology and Ecology 364: 1-10. doi:10.1016/j.jembe.2008.05.015.

Kooijman SALM (2010) Dynamic energy budget theory for metabolic organisation. Edited by S.A.L.M. Kooijman. 3 rd. Cambridge: Cambridge University Press.

Lohrer, A.M., Y. Fukui, K. Wada, and R.B. Whitlatch. 2000. Structural complexity and vertical zonation of intertidal crabs, with focus on habitat requirements of the invasive Asian shore crab, Hemigrapsus sanguineus (de Haan). Journal of Experimental Marine Biology and Ecology 244: 203-217. doi:10.1016/S0022-0981(99)00139-2.

Markert, A., A. Wehrmann, and I. Kröncke. 2009. Recently established Crassostrea-reefs versus native Mytilus-beds: differences in ecosystem engineering affects the macrofaunal communities (Wadden Sea of Lower Saxony, southern German Bight). Biological Invasions 12: 15-32. doi:10.1007/s10530-009-9425-4.

Mascaró, M., and R. Seed. 2001. Choice of prey size and species in Carcinus maenas (L.) feeding on four bivalves of contrasting shell morphology. Hydrobiologia 449: 159-170. doi:10.1023/A: 1017569809818.

McGrorty, S., R.T. Clarke, C.J. Reading, and J.D. Goss-Custard. 1990. Population dynamics of the mussel Mytilus edulis: density changes and regulation of the population in the Exe estuary, Devon. Marine Ecology Progress Series 67: 157-169. doi:10.3354/meps067157.

Miller, R.J. 1990. Effectiveness of crab and lobster traps. Canadian Journal of Fisheries and Aquatic Sciences 47: 1228-1251. doi:10. 1139/f90-143.

Miron, G., D. Audet, T. Landry, and M. Moriyasu. 2005. Predation Potential of the Invasive Green Crab (Carcinus maenas) and other Common Predators on Commercial Bivalve Species found on Prince Edward Island. Journal of Shellfish Research 24: 579-586. doi:10.2983/0730-8000(2005)24[579:PPOTIG]2.0.CO;2.

Moksnes, P.-O. 2002. The relative importance of habitat-specific settlement, predation and juvenile dispersal for distribution and abundance of young juvenile shore crabs Carcinus maenas L. Journal of Experimental Marine Biology and Ecology 271: 41-73. doi:10. 1016/S0022-0981(02)00041-2.

Murray, L.G., R. Seed, and T. Jones. 2007. Predicting the impacts of Carcinus maenas predation on cultivated Mytilus edulis beds. Journal of Shellfish Research 26: 1089-1098. doi:10.2983/07308000(2007)26[1089:PTIOCM]2.0.CO;2.

Naylor, Ernest. 1962. Seasonal changes in a population of Carcinus maenas (L.) in the littoral zone. The Journal of Animal Ecology 31: 601-609. doi:10.2307/2055.

Nehls, G., I. Hertzler, and G. Scheiffarth. 1997. Stable mussel Mytilus edulis beds in the Wadden Sea-they're just for the birds. Helgoländer Meeresuntersuchungen 51: 361-372. doi:10.1007/ BF02908720.

Nehls, G., S. Witte, H. Büttger, N. Dankers, J.M. Jansen, G. Millat, M. Herlyn, et al. 2009. Beds of blue mussels and Pacific oysters. Wadden Sea Ecosystem 25: 1-29.

Pebesma E, and Bivand R (2015) sp: classes and methods for spatial data. $\mathrm{R}$ package version 1.1-1. https://cran.r-project.org/web/packages/ sp/sp.pdf

Philippart, C.J.M., M.S. Salama, J.C. Kromkamp, H.J. van der Woerd, A.F. Zuur, and G.C. Cadée. 2013. Four decades of variability in turbidity in the western Wadden Sea as derived from corrected 
Secchi disk readings. Journal of Sea Research 82: 67-79. doi:10. 1016/j.seares.2012.07.005.

Pickering, T., and P.A. Quijón. 2011. Potential effects of a nonindigenous predator in its expanded range: assessing green crab, Carcinus maenas, prey preference in a productive coastal area of Atlantic Canada. Marine Biology 158: 2065-2078. doi:10.1007/ s00227-011-1713-8.

R Development Core Team. 2015. R: a language and environment for statistical computing. Vienna: R Foundation for Statistical Computing.

Raffaelli, D., A. Conacher, H. McLachlan, and C. Emes. 1989. The role of epibenthic crustacean predators in an estuarine food web. Estuarine, Coastal and Shelf Science 28: 149-160. doi:10.1016/ 0272-7714(89)90062-0.

Reise, K. 1985. Tidal flat ecology. Berlin, Heidelberg: Springer Berlin Heidelberg. doi:10.1007/978-3-642-70495-6.

Rilov, G., and D.R. Schiel. 2006. Trophic linkages across seascapes: subtidal predators limit effective mussel recruitment in rocky intertidal communities. Marine Ecology Progress Series 327: 83-93. doi: $10.3354 /$ meps327083.

Ropes, J.W. 1968. The feeding habits of the green crab, Carcinus maenas (L.). Fishery Bulletin 67: 183-203.

Ruesink, J.L. 2007. Biotic resistance and facilitation of a non-native oyster on rocky shores. Marine Ecology Progress Series 331: 1-9. doi: 10.3354/meps331001.

Ruesink, J.L., H.S. Lenihan, A.C. Trimble, K.W. Heiman, F. Micheli, J.E. Byers, and M.C. Kay. 2005. Introduction of non-native oysters: ecosystem effects and restoration implications. Annual Review of Ecology, Evolution, and Systematics 36: 643-689. doi:10.1146/ annurev.ecolsys.36.102003.152638.

Saraiva, S., J. van der Meer, S.A.L.M. Kooijman, and T. Sousa. 2011. DEB parameters estimation for Mytilus edulis. Journal of Sea Research 66: 289-296. doi:10.1016/j.seares.2011.06.002.

Scherer, B., and K. Reise. 1981. Significant predation on micro- and macrobenthos by the crab Carcinus maenas in the Wadden Sea. Kieler Meeresforschungen Sonderheft 5: 490-500.

Silva, A.C.F., D.M. Boaventura, R.C. Thompson, and S.J. Hawkins. 2014. Spatial and temporal patterns of subtidal and intertidal crabs excursions. Journal of Sea Research 85: 343-348. doi:10.1016/j. seares.2013.06.006.

Smallegange IM (2007) Interference competition and patch choice in foraging shore crabs. Ph.D.-thesis University of Amsterdam, Amsterdam, the Netherlands.

Smallegange, I.M., and J. van der Meer. 2003. Why do shore crabs not prefer the most profitable mussels? Journal of Animal Ecology 72: 599-607. doi:10.1046/j.1365-2656.2003.00729.x.

Smallegange, I.M., and J. van der Meer. 2006. Interference from a game theoretical perspective: Shore crabs suffer most from equal competitors. Behavioral Ecology 18: 215-221. doi:10.1093/beheco/arl071.

Thiel, M., and T. Dernedde. 1994. Recruitment of shore crabs Carcinus maenas on tidal flats: mussel clumps as an important refuge for juveniles. Helgoländer Meeresuntersuchungen 48: 321-332. doi: 10.1007/BF02367044.

Troost, K. 2010. Causes and effects of a highly successful marine invasion: case-study of the introduced Pacific oyster Crassostrea gigas in continental NW European estuaries. Journal of Sea Research 64: 145-165. doi:10.1016/j.seares.2010.02.004.

Tulp, I., L.J. Bolle, E. Meesters, and P. de Vries. 2012. Brown shrimp abundance in northwest European coastal waters from 1970 to 2010 and potential causes for contrasting trends. Marine Ecology Progress Series 458: 141-154. doi:10.3354/meps09743. van de Koppel, J., M. Rietkerk, N. Dankers, and P.M.J. Herman. 2005. Scale-dependent feedback and regular spatial patterns in young mussel beds. The American Naturalist 165: E66-E77. doi:10. $1086 / 428362$.

van der Veer, H.W., J.F.M.F. Cardoso, and J. van der Meer. 2006. The estimation of DEB parameters for various Northeast Atlantic bivalve species. Journal of Sea Research 56: 107-124. doi:10.1016/j.seares. 2006.03.005

van der Zee, E.M., T. van der Heide, S. Donadi, J.S. Eklöf, B.K. Eriksson, H. Olff, H.W. van der Veer, and T. Piersma. 2012. Spatially extended habitat modification by intertidal reef-building bivalves has implications for consumer-resource interactions. Ecosystems 15: 664 673. doi:10.1007/s10021-012-9538-y.

van Stralen M, Troost K, and van Zweeden C (2012) Ontwikkeling van banken Japanse oesters (Crassostrea gigas) op droogvallende platen in de Waddenzee. Rapport 2012.101. MarinX, Scharendijke, the Netherlands.

Walles, B., R. Mann, Ysebaert Tom, K. Troost, P.M.J. Herman, and A.C. Smaal. 2015. Demography of the ecosystem engineer Crassostrea gigas, related to vertical reef accretion and reef persistence. Estuarine, Coastal and Shelf Science 154: 224-233. doi:10.1016/j. ecss.2015.01.006.

Walne, P.R., and G. Davies. 1977. The effect of mesh covers on the survival and growth of Crassostrea gigas Thunberg grown on the sea bed. Aquaculture 11: 313-321. doi:10.1016/0044-8486(77) 90080-1.

Walton, W.C., C. MacKinnon, L.F. Rodriguez, C. Proctor, and G.M. Ruiz. 2002. Effect of an invasive crab upon a marine fishery: green crab, Carcinus maenas, predation upon a venerid clam, Katelysia scalarina, in Tasmania (Australia). Journal of Experimental Marine Biology and Ecology 272: 171-189. doi:10.1016/S0022-0981(02) 00127-2.

Warman, C.G., D.G. Reid, and E. Naylor. 1993. Variation in the tidal migratory behaviour and rhythmic light-responsiveness in the shore crab, Carcinus maenas. Journal of the Marine Biological Association of the United Kingdom 73: 355-364. doi:10.1017/ S0025315400032914.

Waser, A.M., W. Splinter, and J. van der Meer. 2015. Indirect effects of invasive species affecting the population structure of an ecosystem engineer. Ecosphere 6: 109. doi:10.1890/ES14-00437.1.

Waser, A.M., S. Deuzeman, A.K. wa Kangeri, E. van Winden, J. Postma, P. de Boer, J. van der Meer, and B.J. Ens. 2016a. Impact on bird fauna of a non-native oyster expanding into blue mussel beds in the Dutch Wadden Sea. Biological Conservation 202: 39-49. doi:10. 1016/j.biocon.2016.08.007.

Waser, A.M., M.A. Goedknegt, R. Dekker, N. McSweeney, J.I.J. Witte, J. van der Meer, and D.W. Thieltges. 2016b. Tidal elevation and parasitism: patterns of infection by the rhizocephalan parasite Sacculina carcini in shore crabs Carcinus maenas. Marine Ecology Progress Series 545: 215-225. doi:10.3354/meps11594.

Wickham, H. 2009. ggplot2: Elegant Graphics for Data Analysis. New York: Springer New York. doi:10.1007/978-0-387-98141-3.

Williams, M.J., and B.J. Hill. 1982. Factors influencing pot catches and population estimates of the portunid crab Scylla serrata. Marine Biology 71: 187-192. doi:10.1007/BF00394628.

Wolf, F. 1998. Red and green colour forms in the common shore crab Carcinus maenas (L.) (Crustacea: Brachyura: Portunidae): theoretical predictions and empirical data. Journal of Natural History 32: 1807-1812. doi:10.1080/00222939800771311. 